\title{
An aid to development?
}

How can science be made to help poor countries? Alastair Hay looks at part of the UK and Commonwealth effort

TWO international conferences in past month have tried to resolve the problems involved in dividing the spoils of the world between rich and poor. The first meeting, the Conference on International Economic Cooperation or 'north-south' dialogue in Paris, failed to live up to expectations. The second, the Commonwealth Heads of Government meeting in London last week, had less expected of it. Both have hitherto recognised one way or another a role for science and technology in improving the relationship between rich and poor countries. The difference is that the Commonwealth possesses the means to do something about it.

The final communique from the Paris meeting indicated that the ultimate goal sought by poor countries of a new international economic order was a long way off. No figure was put on a common fund to help stabilise raw material prices, a $\$ 1,000$-million aid package fell far below Third World needs, and a general moratorium on Third World debt repayments was refused; on energy the West's goal of discussions between oil producers and consumers was not achieved. But with the countries still talking to each other it was not an unmitigated failure.

Some further progress came from the Commonwealth meeting. And in line with the view that the developed countries will need to provide more aid, the UK Ministry of Overseas Development (ODM) announced a higher contribution to the Comonwealth Fund for Technical Cooperation (CFTC). Through this multilateral development aid fund financed by all Commonwealth governments, the Commonwealth Secretariat supports activities undertaken by such organisations as the Commonwealth Science Council and provides technical assistance in scientific fields to Commonwealth governments. The Commonwealth Science Council (CSC) is the main agency for promoting scientific collaboration between Commonwealth countries, and the increase will have pleased the Commonwealth Secretary General, Shridath Ramphal. In a recent symposium in Brussels on science strategy for Europe he voiced the opinion that "structural change in the world's economic system is the precondition of real development". To achieve the new international economic order which the poor countries were seeking, he said, "an important, indeed an essential and integral element, would be a new, enlightened and dynamic role for science and technology".

The Commonwealth's role in this sphere is not well known, not least because of its minuscule size. The CSC's aim is to increase Commonwealth countries' "national capability : to use science and technology for 0 economic and social development", an onerous task for an organisation with a 1976 budget figure of only $£ 100,000$ provided by its 26 member countries and $£ 20,000$ for project funding by the CFTC. The CSC had its origins in the informal scientific collaboration between Australia, Canada and Britain prior to and during the Second World War. A conference convened by the Royal Society in 1946 placed this collaboration on a more formal basis, and the Council expanded thereafter to incorporate other Commonwealth countries and had several name changes before finally adopting its current title in 1975 . By 1972 with the formation of national science research councils in many developing countries most governments were able to define their development problems more specifically, and this helped the CSC to communicate more effectively with them and especially with the research councils.

The Commonwealth Geological Liaison Office, which publishes reports and a news letter containing information on minerals and geology of interest to Commonwealth countries, and the Permanent Commonwealth Collection of Microorganisms, which promotes the expansion of culture collections and their wider use within the Commonwealth, both function under the aegis of the CSC. Further Commonwealth science collaboration is promoted by the Commonwealth Agricultural Bureau and Institutes which disseminate research information in specialised fields of agricultural science. Two more technologically sophisticated science agencies of the Commonwealth are the Commonwealth Advisory Aeronautical Research Council and the Commonwealth Consultative Space Research Committee. And the Commonwealth Foundation exists to provide grants for specialist conferences, study and research visits, bursaries and lectures.

Like all organisations, the CSC has had its difficulties. A Working Group report in 1974 expressed the view that CSC's work should be expanded but with more coherence than was evident

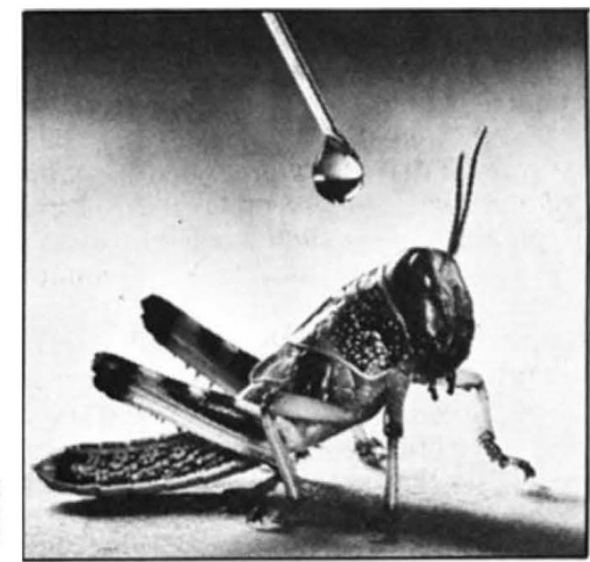

Testing pesticides at the COPR

in the past; in this way it might get across to more scientists in the Commonwealth. Following this gentle upbraiding the CSC streamlined and concentrated its operations. Those of prime concern include standards for engineering and industrial products; industrial research and training; scientific communication and management; mineral exploitation; the technological infrastructure of rural communities; non-conventional energy resources; and preservation and storage of food.

It is a list to daunt many development scientists. The CSC's Executive Secretary since 1972, Gwyn Thomas, who combines his role with that of Scientific Adviser to the Commonwealth Secretary General, agrees that the CSC has a demanding brief, but stresses that its purpose is rather to act as a catalyst than to run specific development projects. The CSC is working towards coverage by organising regional conferences on one or other of these topics, with several interested countries participating. These meetings are held to define common problems and to assist with the formulation of a joint R\&D strategy to solve them. It is also encouraging greater sharing between countries of facilities for industrial training. Member countries train technologists in the use of quality standards and there is a move to promote regional harmonisation of standards. As the CSC sees it, quality standards are essential if exports from developing countries are to be sold in highly competitive Western markets.

\section{Crucial concern}

The subject of food preservation and storage remains one of crucial concern to the CSC. In view of the Council's limited resources in this field, it is again restricted to exhortation and organisation of meetings. But two UK organisations echo CSC interest in this field and are able to participate actively in development programmes; as a result they provide much relevant 
scientific data for food preservation in the developing countries. They are the Centre for Overseas Pest Research (COPR) and the Tropical Products Institute (TPI). Both are scientific units of the UK Ministry of Overseas Development, and as such assist the government of any developing country requesting help. There is a division between their respective roles. The COPR is concerned with pre-harvest food losses, the TPI with the postharvest period.

The COPR is the newer of these two units. Formed in 1971 by the merger of four ministry units concerned with locust, tropical pesticide and termite research, it started life with its component units having over 60 years' experience in overseas pest control. With this background and the resources available to it-the unit's R\&D budget for 1976 was $£ 816,000$-the Deputy Director, Tecwyn Jones, found it logical for COPR to "concentrate on pre-harvest loss control and public health fields involving insect vectors".

Jones's experience of pest and insect vector control in the tropics where harvests and health often cannot be guaranteed without pesticide use makes him conscious of the continuing need for chemical control. The objective is to guarantee farmers' crops in the developing world and to protect the health of the workers in the field. However, the COPR is fully conscious of the dangers and shortcomings of persistent insecticides and recognises the urgent need to search for alternative ways of control and use available insecticides more prudently. To this end it is promoting the use of ultra-low volume spraying of pesticides in the tropics. With this technology, sprays effective for the control of tsetse fly can be reduced from 1,000 grams of pesticide per hectare to as low as 6 grams per hectare. The COPR is presently investigating the use of synthetic pyrethroids as alternatives to such chlorinated hydrocarbons as endosulphan, DDT and dieldrin.

Control of insect pests in the future seems in the COPR's view to lie in the use of a combination of insect pheromones-to disrupt mating and reproduction habits-and viruses which are specific to certain pests. Natural parasites and predators may also have a role to play. A COPR programme to test pheromone/virus control has begun and field trials are to be conducted next year in the Mediterranean area, and in East and Central Africa.

On an international scale the COPR collaborates with UN agencies like FAO and WHO. It acts as a reference centre for FAO on locust migratory patterns, and research in the unit on plant resistance to specific insect pests could provide genetic information of relevance to plant breeders. The unit serves as an international reference centre for WHO for the evaluation of new insecticides for disease vectors such as malaria mosquitoes and tsetse flies, and has an intensive programme to test new molluscicides on the bilharzia parasite.

\section{Broader role}

The larger and older of the ODM units is the TPI. With a history going back to 1894 it has amassed considerable expertise in the field of post-harvest processing, preservation, storage and marketing of tropical products. For most of its existence the institute ministered specifically to the needs of the Commonwealth. However, with its incorporation into ODM in 1965, it was able to participate in work directed to the developing world as a whole.

Malcolm Thain is a deputy director of the TPI and is involved in directing the institute's R\&D work, which in 1976 had a budget of $£ 1,058,000$. He says that the 1975 ODM White Paper 'More help for the poorest' confirmed the TPI in its basic work and that it is generally acknowledged that for Third World crops there is insufficient information on where the losses actually occur in the chain from harvesting to the consumer.

Some of the TPI's research programme is therefore directed towards identifying the weak points in this chain. Inevitably, unfortunate side effects of the green revolution have been identified; varieties of maize especially bred for yield often prove to have poor storage qualities, for example. This has led many Third World farmers to revert to their own lower yielding but better storing varieties. The TPI is thus directing some of their efforts towards the problem of storage of high yield crops. genetic breeding for 'storage properties' as well as yield, and low cost technology for assisting farmers to both dry and store crops. For instance, cassava has a storage life of a few days before

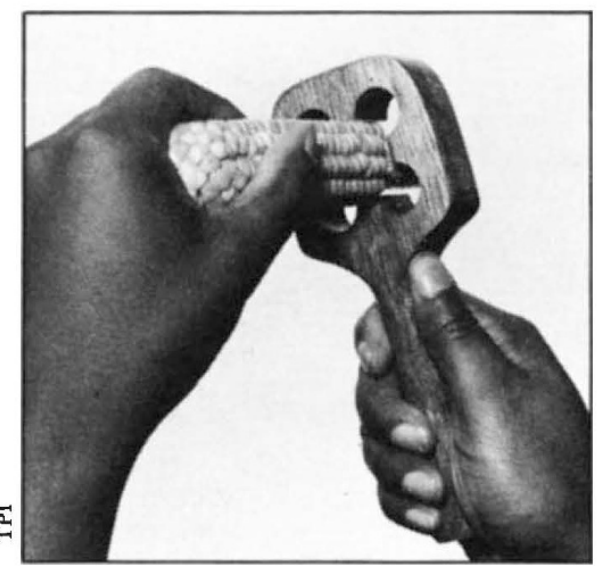

Corn off the $c o b$ decay sets in. TPI scientists have found that a simple earth clamp, similar to that used for storing potatoes, will preserve the crop for up to 3 months.

Other TPI research efforts are concerned with insect pests, again using pheromones as well as fumigation methods, and quality control trials on those foodstuffs of developing countries which have an export potential. One TPI department of increasing relevance to developing country needs is the Industrial Development Department (IDD) near Culham, responsible for most of the ODM research effort on appropriate technology.

David Adair, the head of IDD, is one of those enthusiasts the field of appropriate technology seems to generate. He laments the fact that there is still insufficient grasp of the essential elegance and simplicity of some of the technologies the TPI is working on. Often because they lack the complicated gadgetry of much of today's sophisticated equipment, the items tend to be regarded with a certain air of condescension. However, Adair is not too concerned. Increasing orders for IDD's products is sufficient confirmation of the need for this technology in the developing world. A few of the unit's developments include a still for bay oil extraction which will run on leaves as fuel, a cashew nut processing plant, sunflower seed, cotton seed and groundnut decorticators, simple milling devices, and maize and coconut shredders. IDD places great emphasis on fuel conservation and devotes much attention to alternative sources of fuel like coconut charcoal and to non-conventional building materials.

\section{Demand problem}

Adair's problem-he receives more requests for assistance than he can hope to provide-is common to the TPI as a whole as well as to COPR and CSC. All three concerns publish extensive information about their activities and rely to a considerable extent on publicity to get their message across. But the resources required to meet the needs of the developing world are far greater than those possessed by these three organisations, or indeed by the international organisations or charities.

Development programmes in Third World countries embrace not only science and appropriate technology but sociology, ethology, medicine and economics as well. Integration of these disciplines into aid programmes is now an accepted practice, but personnel and resources are still too limited.

The solution is succinctly put by the Commonwealth Secretary General: "It is not lack of knowledge about what needs to be done, but the will and commitment to do it". 